JHR

36,6

1118

Received 31 January 2021

Revised 5 May 2021

Accepted 7 June 2021

\section{Early marriage and spousal age difference: predictors of preconception health of young married women in Delhi, India}

\author{
Shantanu Sharma \\ Clinical Sciences, Faculty of Medicine, Lund University, Malmö, Sweden, and \\ Faiyaz Akhtar, Rajesh Kumar Singh and Sunil Mehra \\ Mamta Health Institute for Mother and Child, New Delhi, India
}

\begin{abstract}
Purpose - This study aims to assess the associations of early marriage and spousal age difference (independent of early marriage) with reproductive and sexual health and autonomy in decision-making among married women before conception.

Design/methodology/approach - The present study was a part of a three-year community intervention to improve the preconception health of young married women (20-35 years) in the West Delhi district of India. The six key outcomes assessed were: knowledge of reproductive health, discussions related to sexual health, history of anemia, use of contraceptives by women, frequency of consumption of meals per day and the autonomy in decision-making for household expenditures. Unadjusted and adjusted logistic regression models were used to explore the associations between the two key predictors (early marriage or spousal age difference), sociodemographic variables and six outcomes. The results were expressed as odds ratio (OR) and 95\% confidence interval (CI). A total of 2,324 women, enrolled from four wards in the district using cluster-based sampling, were interviewed.

Findings - Around $17 \%$ of women were married by the exact age of 18 , and $20 \%$ were elder or just one year younger than their husbands. Women who were married early had low reproductive health knowledge (OR (95\% CI): 0.48 (0.38-0.60)) and a lower probability of expressing autonomy (OR (95\% CI): $0.78(0.62-0.97)$ ). However, women older than men or younger by just one year in the married relationship had higher reproductive health knowledge (OR (95\% CI): 1.25 (1.01-1.54)) than women younger than men more than two years.
\end{abstract}

Originality/value - Under the umbrella of the preconception care domain, frontline workers should emphasize counseling girls and young women to marry late and delay the first pregnancy.

Keywords Maternal health services, Preconception care, Reproductive health, Women's health, India Paper type Research paper

(c) Shantanu Sharma, Faiyaz Akhtar, Rajesh Kumar Singh and Sunil Mehra. Published in Journal of Health Research. Published by Emerald Publishing Limited. This article is published under the Creative Commons Attribution (CC BY 4.0) licence. Anyone may reproduce, distribute, translate and create derivative works of this article (for both commercial and non-commercial purposes), subject to full attribution to the original publication and authors. The full terms of this licence may be seen at http:// creativecommons.org/licences/by/4.0/legalcode

The authors would like to thank the participants of this study for contributing their time. In addition, the authors are grateful for the assistance of field investigators for their help with data collections, district team lead for their support to field investigators and Manish and Rohit for data management. The study was a part of implementation science in the project supported by Philips India Ltd. under corporate social responsibility. However, the funder did not contribute to the study design, conduct of the study, analysis of samples or data, interpretation of findings or the preparation of the manuscript. 


\section{Introduction}

The continuum of care model for reproductive health proposes service delivery to mothers and children from the preconception period until early childhood [1]. Antenatal care, postnatal care and early childhood care have largely been addressed both at the community and policy levels. However, preconception care has been unaddressed and is now an emerging area of focus [2]. Preconception exposures before pregnancy have longterm consequences, even beyond the pregnancy, on the health of children [3]. The Lancet review on preconception health spotlights preconception risk factors and their effects on maternal and child health by considering the timing and duration of exposures [2]. Obesity, lack of physical activity, unhealthy diet, alcohol or tobacco intake and malnutrition are established preconception risk factors [2]. Most of the evidence on preconception care research comes from high-income countries [4]. The evidence on preconception health interventions from the low- and middle-income countries, particularly India, is emerging [5]. One of the several components in the preconception care intervention package is to delay the first pregnancy and avoid rapid and successive pregnancies. Too early and unwanted pregnancies are influenced by cultural norms that support early marriages [3]. Early marriage is known to have reproductive health and psychological consequences. Studies have found associations between early marriage and low contraceptive use, high fertility, unintended pregnancies and low decision-making power related to sexual and reproductive health rights $[6,7]$. Additionally, child brides have low reproductive health knowledge and autonomy that influence the uptake of health services and make them vulnerable to risky pregnancies [8].

Spousal healthy relations are important for living a successful married life, which may also be influenced by the age gap between the partners. The spousal age difference is critical to understand the power and relation dynamics between a couple that may affect the sexual and reproductive health outcomes of both men and women [9]. Studies suggest differing associations between increased spousal age difference with reproductive health outcomes. For instance, with the increasing spousal age difference, intimate partner violence is reduced as men are expected to be mature. In women-older marriages, there is a reduced birth interval as women use their autonomy. On the contrary, there is evidence of the positive association between spousal age difference and fertility, HIV/AIDS transmission and spousal violence [10].

Given the limited evidence on the effect of early marriage on health outcomes or how spousal age difference affects reproductive health outcomes in women, we decided to explore this gap through a cross-sectional study. Though cross-sectional study design is not ideal as it does not establish causality and is subjected to recall or non-response bias, but it is costeffective, fast and easier to perform, and useful to generate hypothesis [11]. Our study aimed to investigate the associations of early marriage and spousal age difference (independent of early marriage) with reproductive and sexual health, nutrition outcomes and autonomy in the decision-making of married women before conception.

\section{Methodology \\ Study setting}

We carried out the situational analysis in the urban slum settings of West Delhi district, India, in 2016 and 2017. West Delhi district, with a population of 2,580,000, has poor reproductive, maternal and child health indicators compared to the state averages. Around $16 \%$ of married women (15-49 years) had unmet needs for contraception, $54 \%$ of pregnant women had an antenatal check-up within the first trimester and only $36.7 \%$ of under-three children had been breastfed within $1 \mathrm{~h}$ of birth. Nearly $17 \%$ of women (18-29 years) in Delhi were first married by the exact age of 18 [12].
Early marriage and spousal age difference 
It was a cross-sectional study. Data were collected as a part of the three-year community intervention to improve the preconception health of young married women. The intervention involved a peer-led approach to engaging and educating women. The program incorporated education sessions on family planning, preconception care, nutrition, sexually transmitted diseases, pregnancy care, gender-based violence and hygiene.

\section{Sample size and sampling}

Cluster-based sampling was employed to select households (sampling units). According to the population statistics data, West Delhi has 53 wards. Because this study was the baseline survey for an intervention, four wards in the West Delhi district were purposively selected, which had a large population of marginalized people, were adjacent to each other and had access to maternal and child care centers and health facilities. One colony in each of the four wards was selected randomly. Around 7-8 clusters in each of the four colonies and 80 households in each cluster were selected. The households were selected randomly. The sample size of 2,300 was based on pre-calculated figures required to achieve the intervention target.

\section{Survey methods}

Inclusion criteria: We aimed to interview all married women (20-35 years) living in the study area who were neither pregnant nor lactating at the time of the interview.

Recruitment process: There were ten female field investigators in the team; each visited households and identified study participants. After obtaining the consent for participation, field investigators conducted the survey in the local language (Hindi).

\section{Survey instrument development}

The instrument included questions on sociodemographic characteristics, knowledge and practices related to reproductive and sexual health, the autonomy of decision-making for household expenditure, history of anemia and frequency of consumption of meals per day. The participants were asked if they had ever been diagnosed anemic by a doctor/nurse/ midwife. The sociodemographic characteristics included age at the time of the interview, age at marriage, education status, social class (caste), and religion of women, and age at the time of the interview and education status of the husband, household income and source of family income. The knowledge of reproductive health was assessed using five questions: heard of any spacing method, limiting method, HIV/AIDS, sexually transmitted infections/ reproductive tract infections (STI/RTIs) and ideal age of women for the first-time pregnancy. The responses of all these questions were dichotomous (yes/no), except for the ideal age of first-time pregnancy, which had five responses (less than 15, 16-18, 19-20, more than 20 years and do not know). The "yes" responses of the first four questions and the "more than 20 years" response to the ideal age of first-time pregnancy were given a score of 1 . The scores of all five questions were summed up to calculate the aggregate score of "knowledge of reproductive health."

Women were asked about using different contraceptives at the time of the interview, namely, intrauterine devices, oral pills, injectable and other traditional methods. The questions in the sexual health domain were: discussion of any topic related to physical relation with husband (sometimes, always, never and no response) and husband paying attention toward sexual desires (sometimes, always, never and no response). The "always" and "sometimes" responses were scored 2 and 1, respectively, and the other two response categories were given a score of 0 . The scores of the two questions were summed up to 
calculate the aggregate score of the "sexual health" domain. The final scores of both the knowledge of reproductive health and sexual health domains were categorized into high or low score categories using visual binning in SPSS (based on the 50th percentile). The low and high score categories for reproductive health knowledge had the following values: $0-3$ and $4-$ 5 , respectively. Similarly, the low and high score categories of the sexual health domain had values of $0-2$ and $3-4$, respectively.

\section{Key exposure variables or predictors}

Early marriage: Age of women less than 18 years at the time of marriage, irrespective of the age gap between couples. The variable was dichotomized into yes and no.

Spousal age difference: It was categorized as the age difference between wife and husband of one or less than one year and more than one year if the wife is $>18$ years of age at the time of marriage. We did not include women with early marriage $(<18$ years) while creating this group.

\section{Key outcome variables for preconception health}

There were six outcome variables: Knowledge of reproductive health, sexual health, history of anemia, use of contraceptives by females, frequency of consumption of meals per day and autonomy.

\section{Data management and statistical methods}

The data were entered and analyzed in SPSS for Windows version 25.0 (IBM Corp., USA). Descriptive data were expressed as mean (SD) for continuous variables and percentages for categorical variables. We sought distribution of sociodemographic and outcome variables across the total population, women with early marriage and women with the spousal age difference of one or less than one year. The unadjusted model of logistic regression was used to explore the associations between the exposures/predictors, sociodemographic variables and six outcomes. Furthermore, logistic regression was employed to explore the associations among the exposures and outcomes after adjusting for sociodemographic variables, namely, the education status of the wife, family income, social class and religion. Age of wife and education status of the husband were not included in the adjusted analysis as they had interactions with exposures (found in sensitivity analysis). Standard regression coefficients $(\beta)$ and $95 \%$ confidence intervals (CIs) were used to depict the strength and precision of associations. A two-tailed $p$-value $<0.05$ was considered significant.

\section{Ethical consideration}

The study was an extension of the research granted ethical approval by the MAMTA Ethical Review Board (MERB/Sep.2016/002).

\footnotetext{
Results

A total of 2,324 women were interviewed for the survey. Around $17 \%$ of women were married by the exact age of 18 years (Table 1 ). One-fifth of women (468 out of 2,324) were older or just one year younger than their husbands, apart from the early marriage cases. Of 2,324 women, $78 \%$ belonged to Hindus. The mean (SD) age of women with early marriage was 25.5 (4.5) years. Nearly one-third of women with early marriage were illiterate compared to $8 \%$ of women with the spousal age difference of one or less than one year. Around $80-84 \%$ of women in all the groups had monthly family income between INR5,000 and INR10,000.
}

Early marriage and spousal age difference 


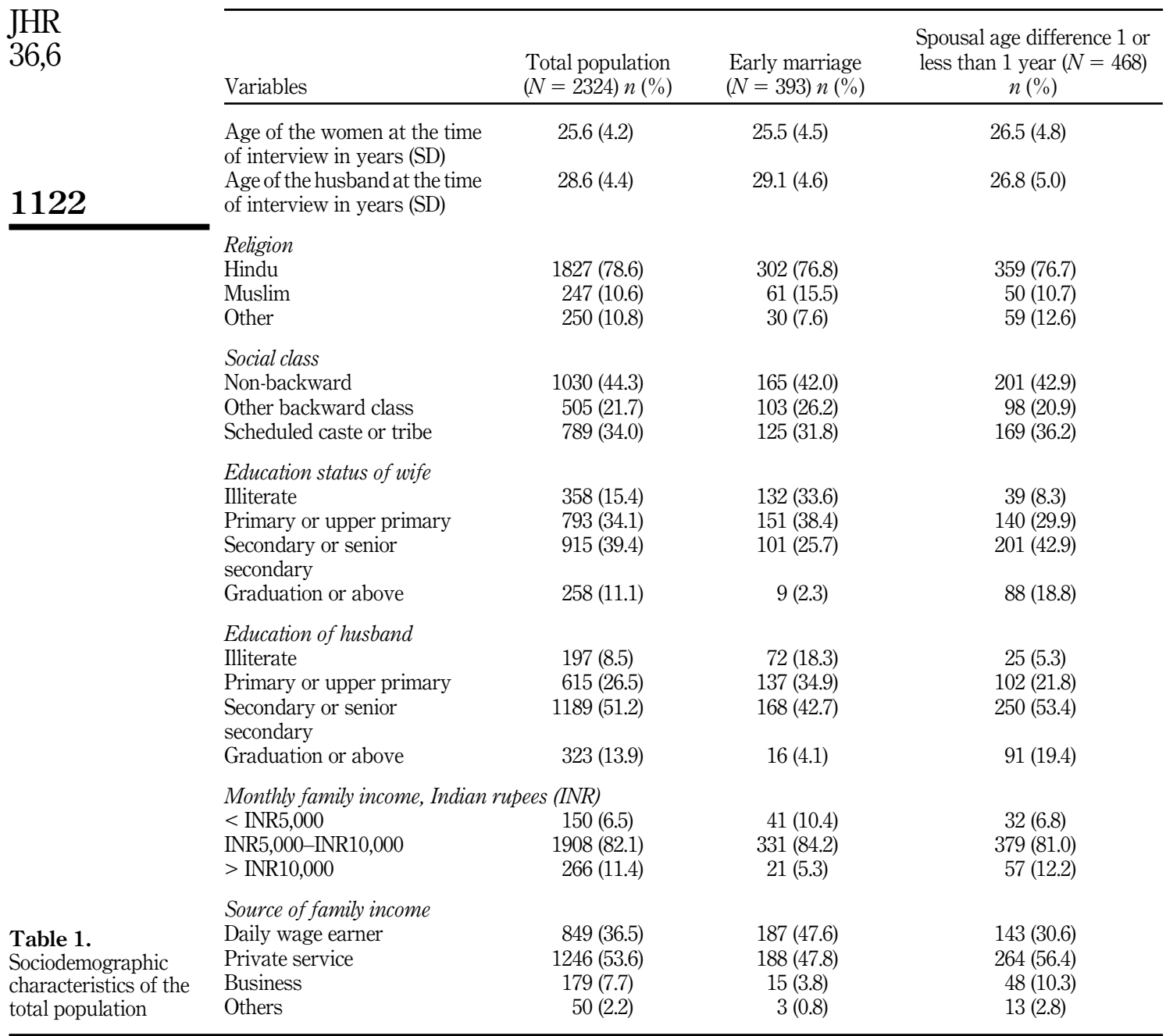

Approximately half of all the women had low and high scores of reproductive health knowledge (Table 2). On the contrary, nearly two-thirds of women with early marriage had low scores of reproductive health knowledge. Further, $16 \%$ of women with the spousal age difference of one or less than one year were using contraceptives at the time of the interview compared to $19.8 \%$ of women with early marriage. Furthermore, more than two-thirds of women had low scores of sexual health domain; thereby, a smaller number of women had discussions with husbands about sexual desires or physical relations.

Tables 3 and 4 show both the unadjusted and adjusted analysis of logistic regression between early marriage or spousal age difference (one or less than one) and the six outcomes. Early marriage, both before and after adjustments, was inversely associated with good knowledge of reproductive health. Women elder to husbands or younger than one year had high knowledge of reproductive health than the counterparts. On the contrary, the spousal age difference of one or less than one year was inversely associated with high 


\begin{tabular}{|c|c|c|c|c|}
\hline Variables & $\begin{array}{l}\text { Total population } \\
(N=2,324) n(\%)\end{array}$ & $\begin{array}{l}\text { Early marriage; yes } \\
\quad(N=393) n(\%)\end{array}$ & $\begin{array}{c}\text { Spousal age difference } 1 \text { or less than } 1 \\
\text { year; yes }(N=468) n(\%)\end{array}$ & $\begin{array}{l}\text { Early marriage } \\
\text { and spousal }\end{array}$ \\
\hline \multicolumn{4}{|c|}{ Knowledge of reproductive health } & \multirow{3}{*}{ age difference } \\
\hline $\begin{array}{l}\text { Low score } \\
(0-3)\end{array}$ & $1,181(50.8)$ & $257(65.4)$ & $204(43.6)$ & \\
\hline $\begin{array}{l}\text { High score } \\
(4-5)\end{array}$ & $1,143(49.2)$ & $136(34.6)$ & $264(56.4)$ & \\
\hline \multicolumn{4}{|c|}{ Contraceptive use by females } & \\
\hline Yes & $447(19.2)$ & $78(19.8)$ & $75(16.0)$ & \\
\hline No & $1,877(80.8)$ & $315(80.2)$ & $393(84.0)$ & \\
\hline \multicolumn{4}{|l|}{ Sexual health } & \\
\hline $\begin{array}{l}\text { Low score } \\
(0-2)\end{array}$ & $1,644(70.7)$ & $273(69.5)$ & $346(73.9)$ & \\
\hline $\begin{array}{l}\text { High score } \\
(3-4)\end{array}$ & $680(29.3)$ & $120(30.5)$ & $122(26.1)$ & \\
\hline \multicolumn{5}{|c|}{ Autonomy of decision-making for household expenditures } \\
\hline Yes & $1,508(64.9)$ & $236(60.1)$ & $306(65.4)$ & \\
\hline No & $816(35.1)$ & $157(39.9)$ & $162(34.6)$ & \\
\hline \multicolumn{4}{|c|}{ History of anemia } & \multirow{7}{*}{$\begin{array}{r}\text { Table 2. } \\
\text { Preconception health } \\
\text { status of all the women, } \\
\text { of the women with } \\
\text { early marriage and } \\
\text { spousal age difference } \\
\text { of one or less than } \\
\text { one year }\end{array}$} \\
\hline Yes & $799(34.4)$ & $117(29.8)$ & $186(39.7)$ & \\
\hline No & $1,055(45.4)$ & $195(49.6)$ & $209(44.7)$ & \\
\hline Do not know & $470(20.2)$ & $81(20.6)$ & 73 (15.6) & \\
\hline \multicolumn{4}{|c|}{ Number of meals per day } & \\
\hline$<3$ & $422(18.2)$ & $75(19.1)$ & $97(20.7)$ & \\
\hline$\geq 3$ & $1,902(81.8)$ & $318(80.9)$ & $371(79.3)$ & \\
\hline
\end{tabular}

scores for sexual health domain and contraceptive use; however, the association was not statistically significant. This seems as older women or women close to the age of husbands are less likely to have a discussion on sexual desires or relationships with husbands and also less likely to use contraceptives. Women with early marriage have lower odds of having the autonomy to make decisions regarding household expenditures $(\operatorname{Exp} \beta(95 \% \mathrm{CI})$ : $0.78(0.62-0.97))$.

In the unadjusted analysis, we found that less-educated wives and husbands, women with low family income and non-Hindus had low reproductive health knowledge than their counterparts (Table 3). With the increasing age of the wife, income and education status of the wife, autonomy to make decisions regarding household expenditures among women was higher than their counterparts (Table 3). Non-Hindus and non-backward or other backward sections had better sexual health discussions than their counterparts (Tables $3-5)$. In the unadjusted analysis, we found that increasing the wife's age and education of husbands too had increased odds of sexual health discussions among couples (Table 3). Higher family monthly income was associated with an increased number of meals per day (Tables 3-5). Contraceptive use was higher among women who belonged to the non-backward section than those who belonged to scheduled caste/tribes (Tables 3-5). In the unadjusted analysis, increasing age was positively associated with increased contraceptive use (Table 3 ).

\section{Discussion}

We have undertaken the study to assess the associations of early marriage and spousal age differences, with key components of preconception health of young married women. Our 


\begin{tabular}{l}
$\mathrm{JHR}$ \\
$\mathbf{3 6 , 6}$ \\
$\mathbf{1 1 2 4}$ \\
\hline
\end{tabular}

Table 3.

Unadjusted model of logistic regression to assess the link of early marriage, spousal age difference and other exposures with preconception health outcomes

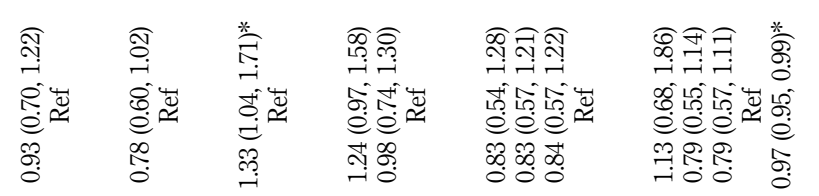

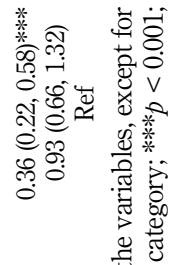

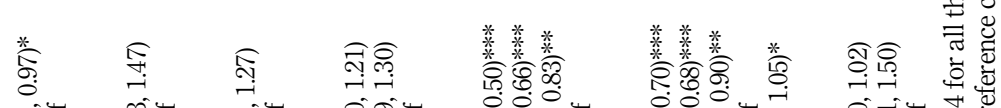

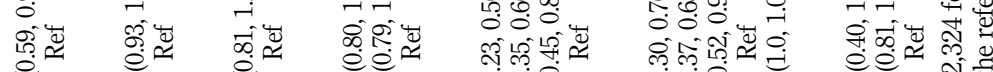

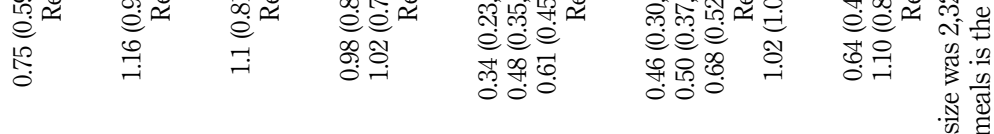

尊

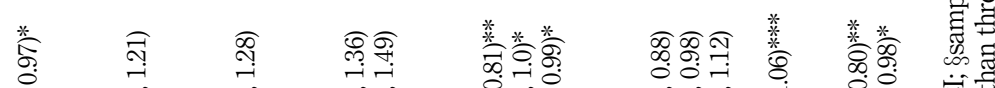

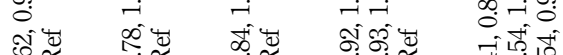

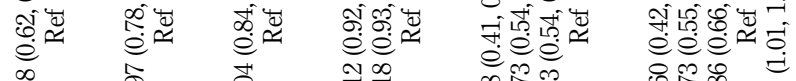

文 S.

극ำ

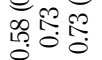

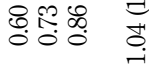

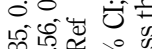

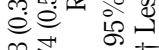

绝孛

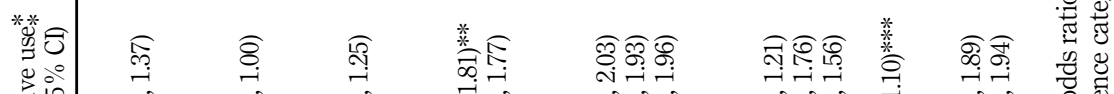

ब虫

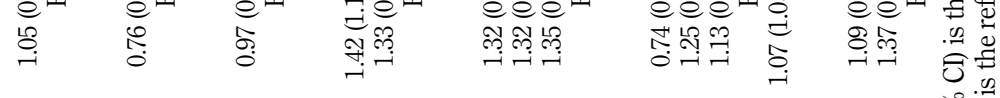

鄫福

E0 0 क

焉

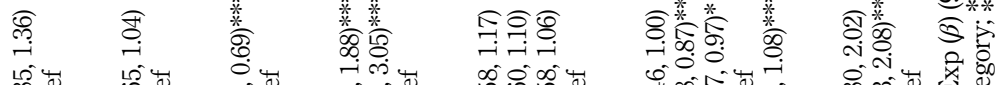

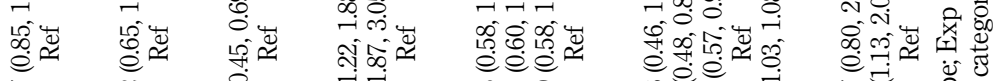

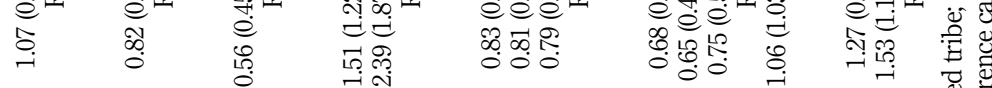

焉

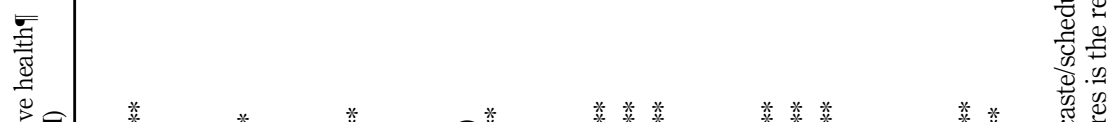

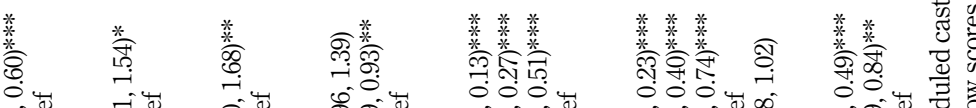

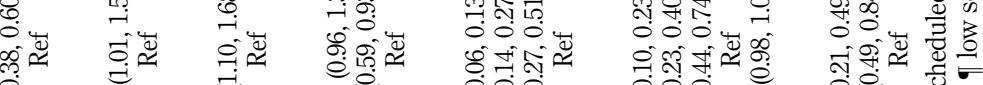
仓

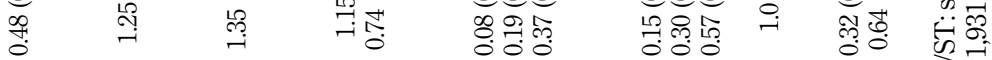

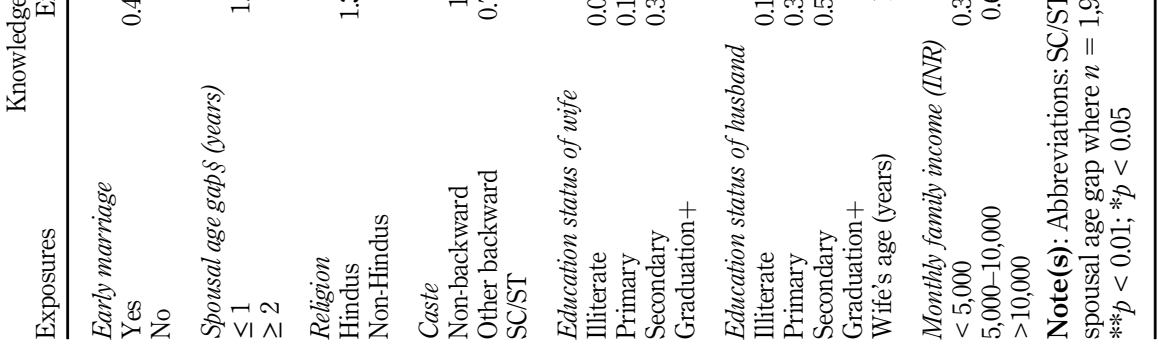




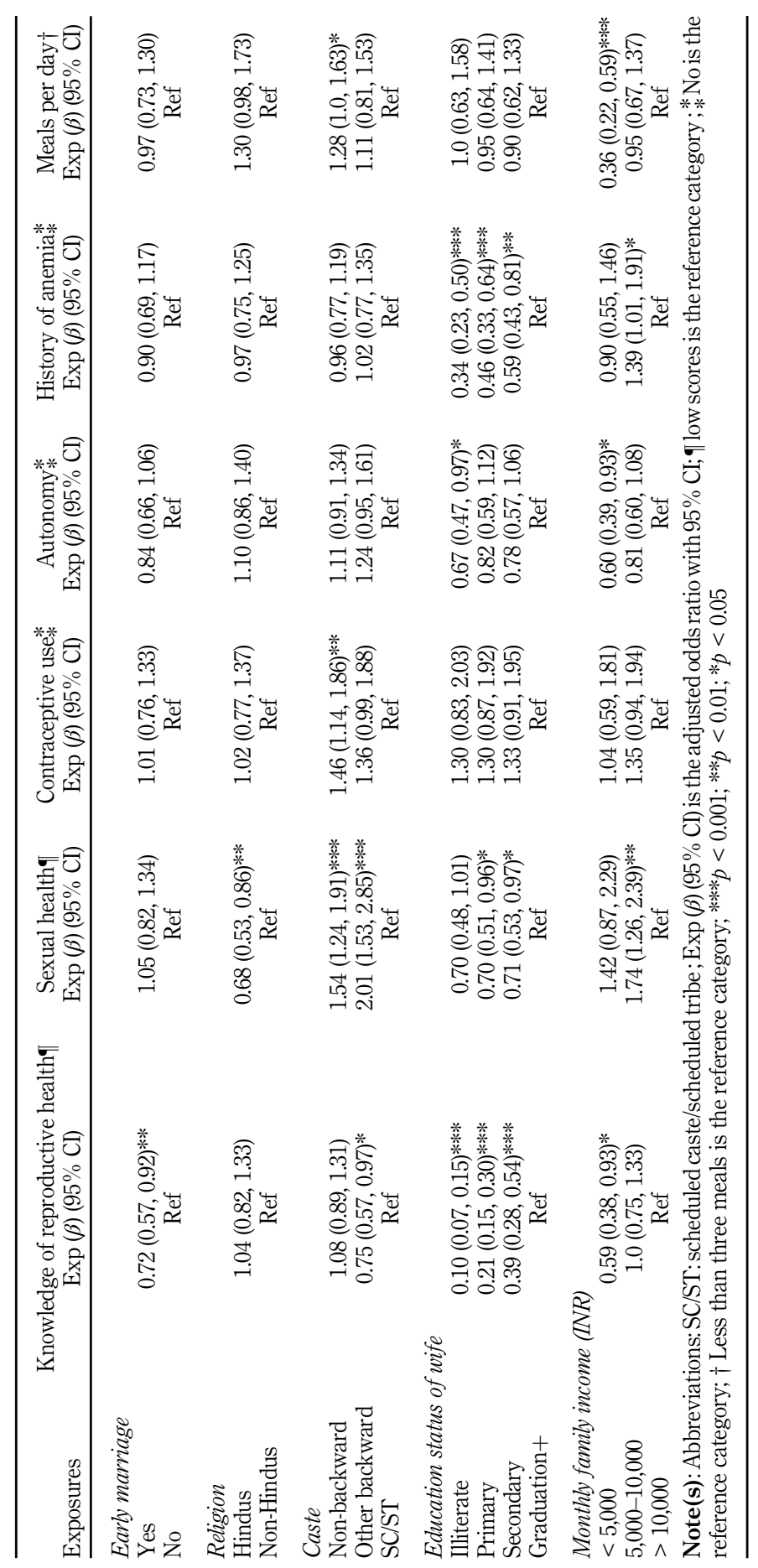

Early marriage and spousal age difference

1125

Table 4. Adjusted model of logistic regression to assess the link of early marriage and other exposures with preconception health outcomes $(n=2,324)$ 
JHR
36,6

1126

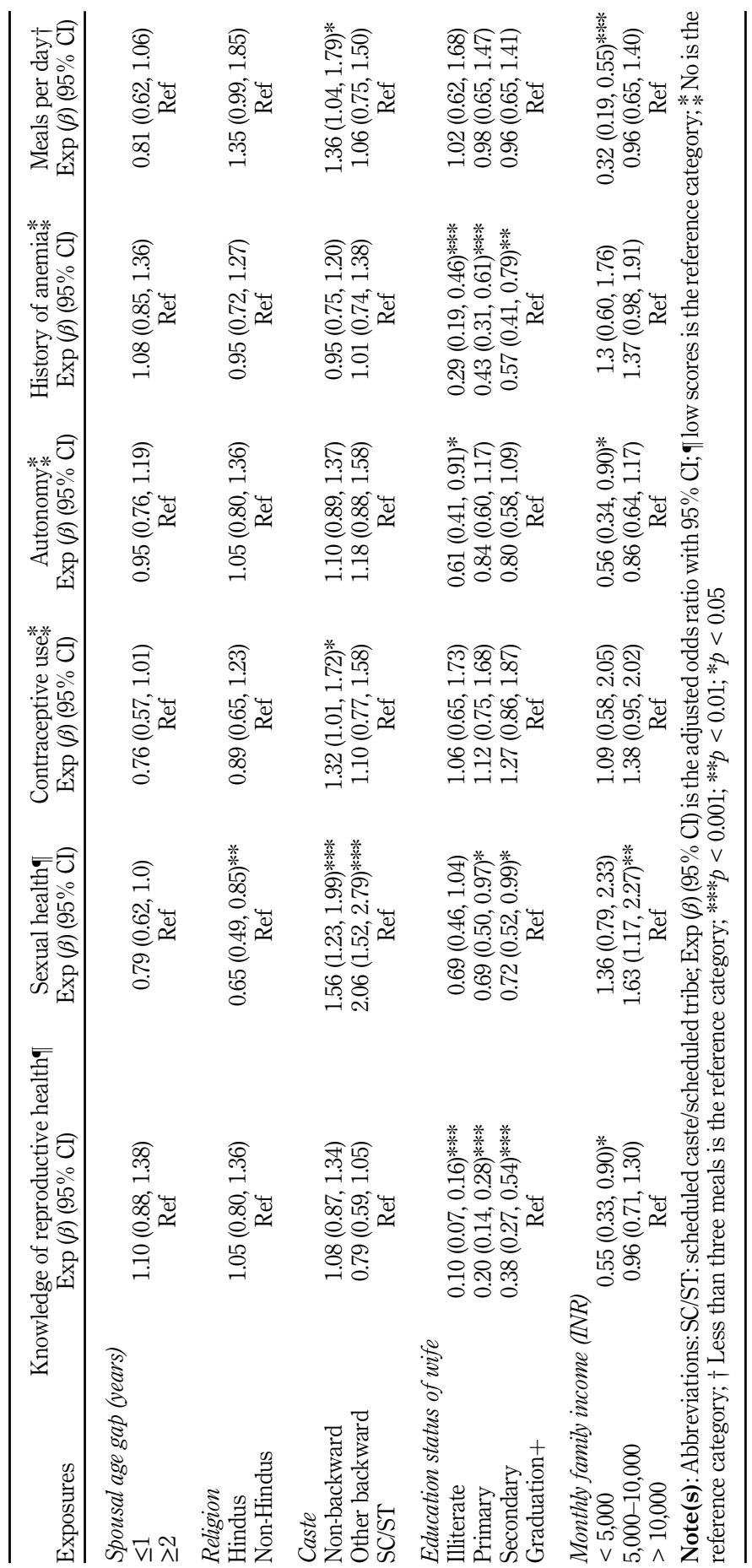

Table 5.

Adjusted model of logistic regression to assess the link of spousal age gap and other exposures with preconception health outcomes $(n=1,931)$

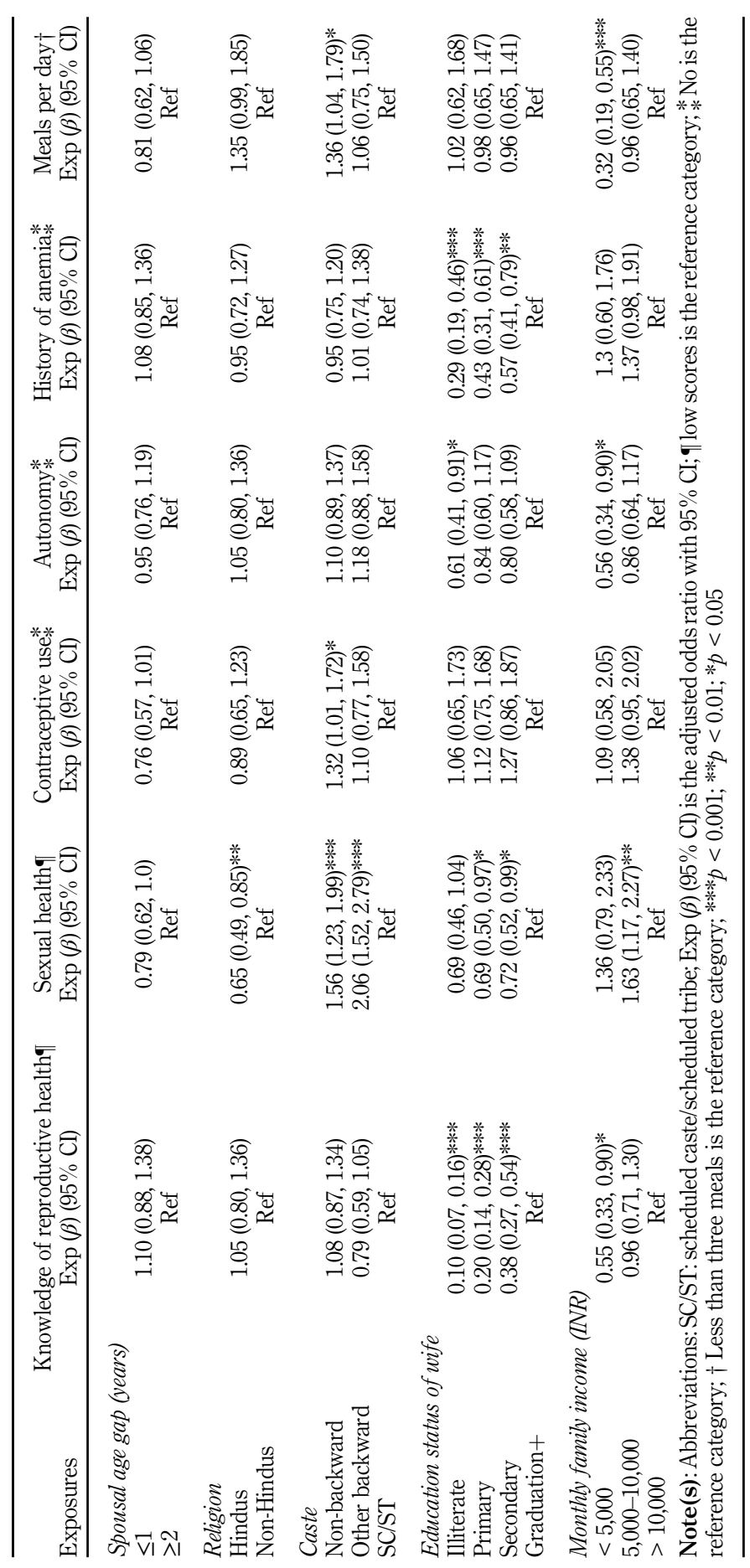


study provides evidence of the consequences of both early marriage and large spousal age difference on the reproductive health and autonomy of women. We found that women who were married early had low reproductive health knowledge and a lesser probability of autonomy in decision-making for household expenditures. Similarly, women older than men or younger by just one year in the married relationship had higher reproductive health knowledge.

More than two-thirds of women in the early marriage group were illiterate or had obtained education only up to the primary level (less than five years of formal schooling). This proportion of uneducated or low educated women in the early marriage group was nearly double the proportion of women in spousal age difference of one or less than the one year group. Similarly, a higher proportion of women with early marriage had the lowest tertile of monthly family income $(10.4 \%)$ compared to the other group $(6.8 \%)$. These findings are congruent with the previous study that reported higher odds of early marriage in women with no formal education (odds ratio, $4.22 ; 95 \%$ CI: 2.51-7.11) and with the lowest tertile of family income (odds ratio, 3.49; 95\% CI: 2.04-5.98) [13]. A greater proportion of the husbands of child brides were also uneducated compared to the other group in our study. This concurs with other studies reporting early marriage to be pronounced among uneducated women and their husbands $[13,14]$.

The use of contraceptives among women was higher (19\%) in our study compared to the national survey $(14.7 \%)$ and another study from urban Delhi $(11.7 \%)[12,15]$. On the contrary, $51 \%$ of women had high knowledge of reproductive health, which is very low compared to the other studies $[12,16]$. This reflects a low use of contraceptives despite high knowledge about reproductive health issues, including contraceptives. We argue that the contraceptive uptake is low among young married women who are newly married or have not completed the family. In the past ten years, there has not been a significant change in the uptake of contraceptives among young married women, and sterilization continues to dominate the contraceptive method mix [12]. Nearly two-thirds of women had the autonomy to make decisions related to household expenditure in the present study. This is crucial to understand as women who have access to spending money have improved reproductive decision-making power and freedom of movement to access family planning services.

Women with early marriage, limited by low levels of education and skills, have lesser negotiation skills and self-efficacy to excise reproductive health decision-making and hence are vulnerable to high fertility, mortality and violence [7]. Intentionally, early marriages are driven by the desire to control female sexuality and thoughts that women are somehow inferior to men [17]. Married girls are often not considered capable of making financial decisions by their husbands, and those who work outside may not have control over their earnings [18].

The use of contraceptives by women is influenced by multiple interlinked sociodemographic, cultural and economic factors in the communities. Besides age and spousal relationships, contraceptive use depends on the standards of living, religion, number of surviving children and their availability [19]. Often, there is a large age difference between women with early marriages and their husbands, which disempower the wife. However, our results suggest that women elder to husbands or younger by one year have improved reproductive health knowledge, but the lesser probability of sexual health discussions and use of contraceptives than their counterparts. After adjusting for the education status of women, the statistical difference for improved knowledge disappeared. We argue that women elder to husbands have less probability of using contraceptives themselves and may influence husbands to use condoms instead. Our thoughts are supported by the previous results stating that condom negotiation is influenced by women, and men alone do not dominate the decision on its use [20,21]. This indirectly highlights greater reproductive control by women in relation to husbands of equal age or younger to them. However, other 
JHR

36,6

studies suggest a large spousal age difference as a risk factor for increased HIV prevalence among women, intimate partner violence and high family [9, 22]. But, it should be considered that the spousal age difference in these studies was not calculated independent of early marriage.

Child brides are nutritionally vulnerable as they are undergoing the phase of rapid growth and development during adolescence. They are vulnerable to anemia, undernutrition and their adverse consequences. Furthermore, pregnancy and lactation during adolescence may lead to stunting, loss of weight and micronutrient deficiencies [18]. However, our study did not obtain any significant effect of either early marriage or spousal age difference on anemia (after adjustments) or frequency of consumption of meals. Nevertheless, our findings would not firmly disregard or approve of such associations in the previous studies because the information in our study inadequately covered the nutritional outcomes. The question related to anemia was based on the recall history by women and not the testing of hemoglobin levels. Similarly, the consumption of meals per day is a crude question to assess the quality of dietary intake among populations. But, increasing monthly family income had a strong positive association with higher meal frequency, which reflects an increased availability of food with increasing purchasing power [23].

Congruent with other studies, we found that the education status of women and husbands is crucial for improved reproductive health knowledge, sexual health discussions and increased women's autonomy in decision-making $[7,13]$. Our results reiterate the evidence of improved autonomy, contraceptive use and sexual health among women with increasing age $[7,12]$. This advocates for the need to improve education of girls and delayed marriage and first-time pregnancy for healthy preconception health outcomes. Religion and caste have been found in our study to influence reproductive health knowledge, sexual health discussions and the use of contraceptives. This spotlights the need to contextualize interventions with greater emphasis on backward sections for improved preconception health outcomes.

To the best of our knowledge, this is one of the limited studies that assessed the effects of spousal age difference on the reproductive health of young married women. We suggest that there is a growing need to strengthen the multi-sectoral program to stop early marriages and childbearing, emphasize on the reproductive and sexual health rights of women, and address undernutrition and anemia among girls and women.

\section{Limitations}

The results of the study should be interpreted in view of certain limitations. The study area includes a typical urban slum setting, which may conclude findings not generalizable to other settings. As it is a cross-sectional study, it is difficult to infer causality between the predictors and outcomes. The data on exposures and outcomes were limited to certain questions and not comprehensively captured due to resource constraints.

\section{Conclusions}

Although the outcomes were limited to selected variables and data were collected in an urban setting, the results are still conclusive to understand that women should marry late (after 18 years), women should marry men not very elder to her (probably less than two-year difference) and girls need to be educated until graduation or above for improved reproductive health knowledge, increased autonomy and increased contraceptive use. Under the umbrella of the preconception care domain, frontline workers should emphasize counseling girls and young women to marry late and possibly after 20 years of age. We need to empower girls and women so that they have the agency and voice to exercise control over their reproductive and sexual 
health rights. The understanding of how spousal age differences affect different health outcomes is still in its infancy and warrants further research in different cultural settings.

Conflict of Interest: None

Early marriage and spousal age difference

\section{References}

1. Goeres DM, Walker DK, Buckingham-Meyer K, Lorenz L, Summers J, Fritz B, et al. Development, standardization, and validation of a biofilm efficacy test: the single tube method. J Microbiol Methods. 2019; 165: 105694. doi: 10.1016/j.mimet.2019.105694.

2. Stephenson J, Heslehurst N, Hall J, Schoenaker D, Hutchinson J, Cade JE, et al. Before the beginning: nutrition and lifestyle in the preconception period and its importance for future health. Lancet. 2018; 391(10132): 1830-41. doi: 10.1016/s0140-6736(18)30311-8.

3. World Health Organization [WHO]. Preconception care: maximizing the gains for maternal and child health. [updated 2013 Feb; cited 2021 Jan]. Available from: https://www.who.int/publications/ i/item/WHO-FWC-MCA-13.02.

4. Hemsing N, Greaves L, Poole N. Preconception health care interventions: a scoping review. Sex Reprod Healthc. 2017; 14: 24-32. doi: 10.1016/j.srhc.2017.08.004.

5. Lassi ZS, Kedzior SG, Tariq W, Jadoon Y, Das JK, Bhutta ZA. Effects of preconception care and periconception interventions on maternal nutritional status and birth outcomes in low- and middle-income countries: a systematic review. Nutrients. 2020; 12(3): 606. doi: 10.3390/nu12030606.

6. Misunas C, Gastón CM, Cappa C. Child marriage among boys in high-prevalence countries: an analysis of sexual and reproductive health outcomes. BMC Int Health Hum Rights. 2019; 19(1): 25. doi: 10.1186/s12914-019-0212-8.

7. Tadele A, Tesfay A, Kebede A. Factors influencing decision-making power regarding reproductive health and rights among married women in Mettu rural district, South-West, Ethiopia. Reprod. Health. 2019; 16(1): 155. doi: 10.1186/s12978-019-0813-7.

8. Maharjan B, Rishal P, Svanemyr J. Factors influencing the use of reproductive health care services among married adolescent girls in Dang district, Nepal: a qualitative study. BMC Pregnancy Childbirth. 2019; 19(1): 152. doi: 10.1186/s12884-019-2298-3.

9. Adebowale AS. Spousal age difference and associated predictors of intimate partner violence in Nigeria. BMC Publ. Health. 2018; 18(1): 212. doi: 10.1186/s12889-018-5118-1.

10. Olamijuwon EO, Gumbo J. Fertility behaviour in Uganda: does partner age difference matter? Afr. Popul. Stud.. 2016; 30(2): 2473-81. doi: 10.11564/30-2-858.

11. Wang X, Cheng Z. Cross-sectional studies: strengths, weaknesses, and recommendations. Chest. 2020; 158(1S): S65-71. doi: 10.1016/j.chest.2020.03.012.

12. International Institute for Population Sciences [IIPS]; ICF. National family health survey (NFHS-4), 2015-16: India. Mumbai: IIPS; 2017.

13. Bezie M, Addisu D. Determinants of early marriage among married women in Injibara town, North West Ethiopia: community-based cross-sectional study. BMC Wom. Health. 2019; 19(1): 134. doi: 10.1186/s12905-019-0832-0.

14. Hossain MG, Mahumud RA, Saw A. Prevalence of child marriage among Bangladeshi women and trend of change over time. J Biosoc Sci. 2016; 48(4): 530-8. doi: 10.1017/s0021932015000279.

15. Bhilwar M, Lal P, Sharma N, Bhalla P, Kumar A. Prevalence of induced abortions and contraceptive use among married women in an urban slum of Delhi, India. Int J Gynaecol Obstet. 2017; 136(1): 29-32. doi: 10.1002/ijgo.12011.

16. Banerjee SK, Andersen KL, Warvadekar J, Aich P, Rawat A, Upadhyay B. How prepared are young, rural women in India to address their sexual and reproductive health needs? a cross-sectional assessment of youth in Jharkhand. Reprod. Health. 2015; 12: 97. doi: 10.1186/s12978-015-0086-8.

17. Girls Not Brides. Child, early and forced marriage and the control of sexuality and reproduction. [updated 2015 Oct; cited $2021 \mathrm{Jan}$ ]. Available from: https://www.girlsnotbrides.org/learning- 
JHR

36,6

1130

resources/resource-centre/child-early-and-forced-marriage-and-the-control-of-sexuality-andreproduction/\#resource-downloads.

18. Parsons J, Edmeades J, Kes A, Petroni S, Sexton M, Wodon Q. Economic impacts of child marriage: a review of the literature. Rev Faith Int Aff. 2015; 13(3): 12-22. doi: 10.1080/15570274. 2015.1075757.

19. Chaurasia AR. Contraceptive use in India: a data mining approach. Int J Popul Res. 2014; 2014: 821436. doi: 10.1155/2014/821436.

20. Dube N, Nkomo TS, Khosa P. Condom usage negotiation among customarily married women in Katlehong, Johannesburg. SAGE Open. 2017; 7(1): 2158244016687345. doi: 10.1177/ 2158244016687345 .

21. Pullum T, Cleland J, Shah I. Consensus, power and trust in the use of family planning and condoms by couples in Eastern and Southern Africa. In: the XXV International Population Conference of the International Union for the Scientific Study of Population (IUSSP); Tours, France; 2005 July 18-23.

22. Buss DM, Shackelford TK, LeBlanc GJ. Number of children desired and preferred spousal age difference: context-specific mate preference patterns across 37 cultures. Evol Hum Behav. 2000; 21(5): 323-31. doi: 10.1016/s1090-5138(00)00048-9.

23. Zanvar VS, Pradnya D. Influence of socio-economic parameters on food and nutrient intake. Int J Home Sci. 2019; 5(1): 30-3.

\section{Corresponding author}

Shantanu Sharma can be contacted at: shantanusharma145@gmail.com

For instructions on how to order reprints of this article, please visit our website: 